\title{
The Effect of Active Immunization against Inhibin on Gonadotropin Secretions and Follicular Dynamics during the Estrous Cycle in Cows
}

\author{
Mohamed S. MEDAN ${ }^{1,2)}$, Toshiro TAKEDOMI ${ }^{3)}$, Yoshito AOYAGI ${ }^{3)}$, \\ Masato KONISHI ${ }^{3)}$, Shigeto YAZAWA ${ }^{4)}$, Gen WATANABE ${ }^{1,5)}$ and \\ Kazuyoshi TAYA ${ }^{1,5}$ \\ 1) Laboratory of Veterinary Physiology, Department of Veterinary Medicine, Faculty of \\ Agriculture, Tokyo University of Agriculture and Technology, Fuchu, Tokyo 183-8509, \\ ${ }^{2)}$ Department of Theriogenology, Faculty of Veterinary Medicine, Suez Canal University, \\ Ismailia, Egypt, ${ }^{3)}$ Embryo Transfer Center, ZEN-NOH, Hokkaido 080-1407, ${ }^{4)}$ Institute of \\ Animal Health, ZEN-NOH, Chiba 285-0043 and ${ }^{5)}$ Department of Basic Veterinary Science, \\ United Graduate School of Veterinary Sciences, Gifu University, Gifu 501-1193, Japan
}

\begin{abstract}
The hypothesis of the present study is that active immunization of cows against inhibin would neutralize endogenous inhibin, increase circulating levels of follicle stimulating hormone, and subsequently affect follicular dynamics and the ovulation rate during the estrous cycle. Thirteen cows were immunized against inhibin $\alpha$-subunit and, 6 cows were immunized with a placebo. Both groups were given 4 booster immunizations 7,14,21, and 34 weeks after the primary injection. Ovaries were examined daily after the $2 \mathrm{nd}, 3 \mathrm{rd}$, and 4 th booster immunizations by transrectal ultrasonography for 25 days. After the 4 th booster immunization, blood samples were collected daily for one complete estrous cycle to measure FSH and LH. The results showed that the immunized cows generated antibodies against inhibin, and that they had higher FSH levels compared with the controls. The number of follicular waves during the estrous cycle was higher in the immunized cows ( 3 or 4 waves) than in the controls ( 2 or 3 waves). Moreover, the immunized cows had a greater number of follicles during the estrous cycle compared with the control cows. The maximum number of follicles was 14.8 \pm 1.7 vs $5.4 \pm 0.2$ in inhibin-immunized and control cows, respectively, during the first follicular wave and $13.9 \pm 1.9$ vs $5.6 \pm 0.7$, respectively, during the ovulatory wave. Multiple ovulations were increased in the immunized cows. However, the ovulation rate varied greatly in the immunized animals. In conclusion, immunization against inhibin increased FSH secretions during the estrous cycle in the cows. Moreover, the immunized cows had a greater number of follicular waves during the estrous cycle and a greater number of follicles, and this could be used as a potential source of oocytes for use in IVF/embryo transfer programs.
\end{abstract}

Key words: Active immunization, Cows, Follicular wave, FSH, Inhibin

(J. Reprod. Dev. 52: 107-113, 2006)

T he growth, development, and maturation of ovarian follicles is a fundamental process for effective reproduction in farm animals. In cattle, antral follicles grow in a wave-like pattern, with 2 to 3 waves emerging from the pool of small follicles in the ovary during each estrous cycle [1, 2]. Emergence of successive follicular waves during

Accepted for publication: October 21, 2005

Published online: November 18, 2005

Correspondence: K. Taya (e-mail: taya@cc.tuat.ac.jp) 
the estrous cycle is associated with increases in circulating FSH concentrations [3, 4]. Understanding the factors that control ovarian folliculogenesis could lead to development of more precise methods of controlling reproductive cycles in livestock [5].

The FSH surge and the resulting follicular wave that develops at the start of the estrous cycle are termed as the first surge and the first wave. When the largest follicle of a wave reaches a mean diameter of $8.5 \mathrm{~mm}$, the follicles begin to deviate in diameter into a single dominant follicle and several subordinate follicles [6]. The FSH concentrations continue to decrease for approximately 1 day after the start of deviation in follicle diameter. The decrease in FSH concentrations after deviation in follicular diameter apparently assures continued FSH deprivation of the subordinate follicles. In addition, the low FSH concentrations may delay the emergence of the next follicular wave. The depression of circulating FSH during this time has been attributed to the secretion of inhibin and estradiol by the dominant follicle of the wave $[4,6$, 7]. Administration of FSH can be expected to shorten the interval between the 1 st and 2 nd follicular waves. In one study, an FSH-rich pituitary extract administered 5 days after ovulation shortened the interval from treatment to the emergence of the 2nd follicular wave [8]. Also, administration of recombinant bovine FSH reduced the interval to the 2nd follicular wave in cows [9].

Active immunization against inhibin neutralized endogenous inhibin and increased the ovulation rate in several mammalian species, including sheep [10, 11], gilts [12], goats [13], and cows [14-16]. However, the effect of active immunization against inhibin on follicular waves in cows still lacking. Therefore, the aim of the present study was to determine the effect of active immunization against inhibin on the follicular dynamics and gonadotropin secretions in cows.

\section{Materials and Methods}

\section{Animals and blood samplings}

The present study was carried out using 19 Holstein heifers (16-20 mo old, weighing $402.0 \pm 4.6$ $\mathrm{kg}$ ). Thirteen animals were immunized against inhibin, and 6 animals were used as controls.

Blood samples were collected every two weeks during the experimental period to measure inhibin antibody titers. Additional daily blood samples were collected from four immunized and 6 control animals for one complete estrous cycle after the 4 th booster immunization to measure FSH and LH. To detect the LH surge, blood samples were collected every $3 \mathrm{~h}$ from the start of estrus $(0 \mathrm{~h})$ to $87 \mathrm{~h}$ after.

\section{Preparation of the immunogen (inhibin vaccine)}

Inhibin vaccine was obtained by conjugating rabbit serum albumin (RSA) to a polypeptide synthesized by copying the amino acid sequence from the 1 to 26 (numbering from the $\mathrm{N}$-terminal end) positions of the $\alpha$-subunit of porcine inhibin (Institute of Peptide Research, Osaka, Japan). In the inhibin-immunized group, primary injection of the vaccine was carried out as follows: a mixture of 1 $\mathrm{mg}$ of the conjugated peptide (corresponding to a fragment of inhibin) and complete Freund's adjuvant was injected into the animals subcutaneously in 3 to 4 places. Four booster injections (half the amount of the primary injection) were given 49 days (the 1st), 98 days (the 2nd), 147 days (the $3 \mathrm{rd}$ ), and 238 days (the 4 th) after the primary injection. In the control group, the animals were injected in the same way with RSA in complete Freund's adjuvant.

\section{Ultrasound examinations}

Seven or 8 days after estrus, the ovulation rate was confirmed using 10 immunized animals by transrectal ultrasonography (by counting the corpora lutea) for 2 cycles before immunization and 8 cycles after immunization. After the 2 nd, $3 \mathrm{rd}$, and 4 th booster immunization, ovaries were monitored daily for 25 days to monitor follicular dynamics during the estrous cycle. Estrous cycles were synchronized using prostaglandin F $2 \alpha(500$ $\mu \mathrm{g}$ per animal, im) at the $2 \mathrm{nd}, 3 \mathrm{rd}$ and 4 th booster immunizations.

Transrectal ultrasound examination was carried out using an ultrasound scanner (SSD-650CL, Aloka, Tokyo, Japan) equipped with a $5 \mathrm{MHz}$ transducer, as described previously [17].

\section{Assessment of inhibin antibody titers}

Changes in inhibin binding activity in plasma were determined by measuring the binding of ${ }^{125} \mathrm{I}-$ labeled inhibin $(5000 \mathrm{cpm})$, as reproted previously [18]. Plasma samples were diluted 1:50 with PBS containing $5 \%$ BSA. PBS $(100 \mu \mathrm{L})$ was added to 
each aliquot (100 $\mu \mathrm{L})$ of diluted plasma and incubated for $24 \mathrm{~h}$ at $37 \mathrm{C}$ with ${ }^{125}$-labeled bovine 32-kDa inhibin. Bound tracer was then separated by adding $100 \mu \mathrm{L}$ PBS containing $1 \%$ bovine gamma globulin and $500 \mu \mathrm{L}$ PBS containing $25 \%$ polyethylene glycol (Mwt, 6000), mixing for $3 \mathrm{~min}$, and centrifugation at $1200 \mathrm{~g}$ for $30 \mathrm{~min}$ at $4 \mathrm{C}$. Then the radioactivity in the precipitate was counted. Inhibin-binding activity was expressed as a percentage of the sum of the total counts.

\section{Hormone analysis}

Plasma concentrations of FSH were measured by radioimmunoassay (RIA) using anti-bovine $\mathrm{FSH} \beta$ subunit serum (UCB Bioproducts, Braine_l'Alleud, Belgium) and USDA-FSH-BP3 for radioiodination. Results are expressed in terms of USDA-FSH-B1. Plasma concentrations of LH were measured by RIA using antiovine LH (YM 18), USDA-bLH-I-1 for radioiodination, and USDA-bLH-B-5 as a reference standard. The sensitivities of the assay were $1 \mathrm{ng} /$ tube for FSH and $0.02 \mathrm{ng} /$ tube for LH, respectively. The intra- and interassay coefficients of variation were 5.5 and $9.9 \%$ for $\mathrm{FSH}$, and 5.9 and $11.5 \%$ for $\mathrm{LH}$, respectively.

\section{Statistical analysis}

Data are expressed as means \pm SEM. Repeatedmeasures ANOVA followed by Bonferroni test was used to examine the effect of inhibin immunization on hormonal concentrations. Student's t-test was used to compare between the inhibin-immunized and control groups for the number and diameter of follicles. A probability value $(P)$ of less than 0.05 was considered significant. All statistical analyses were performed using the SAS software package [19].

\section{Results}

\section{Plasma anti-inhibin titers}

The time course of antibody development in the immunized cows as determined by binding of the ${ }^{125}$ I-labeled bovine inhibin is shown in Fig. 1. Antibodies that bound ${ }^{125}$ I-labeled bovine inhibin were produced by all cows receiving the inhibin vaccine. Titers rose after the 2 nd booster injection in the immunized cows. In contrast, antibody titers in the control group remained the same as before immunization.

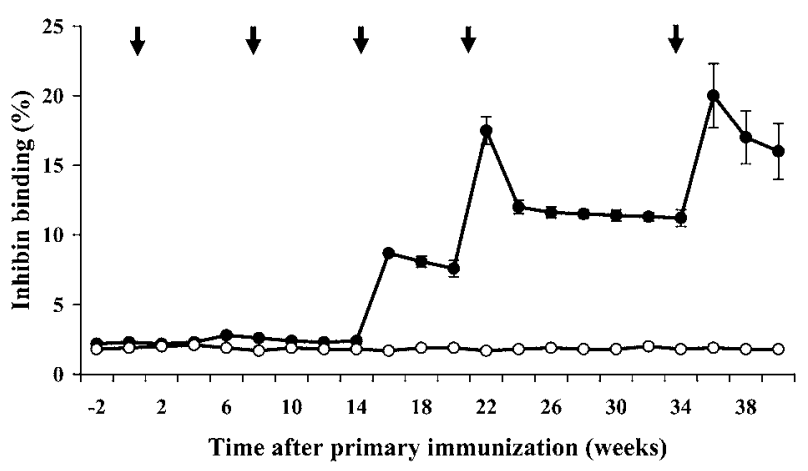

Fig. 1. Binding activity of inhibin antibody (measured at 1:50 dilution) in the circulation of heifers immunized against inhibin (solid circles; $\mathrm{n}=13$ ) or rabbit serum albumin (open circles; $n=6$ ). Arrows indicate the time of immunization.

\section{Plasma concentrations of FSH and $\mathrm{LH}$}

Plasma concentrations of FSH and $\mathrm{LH}$ in the inhibin-immunized and control cows during the estrous cycle after the 4 th booster immunization are shown in Figs. 2 a and b. There was a significant $(P<0.01)$ increase in the plasma concentration of FSH during most days of the estrous cycle in the inhibin-immunized cows (Fig. 2a). On the other hand, the plasma concentrations of LH did not differ significantly between the inhibin-immunized and control cows (Fig. 2b).

Effect of immunization against inhibin on follicular dynamics, number of follicles and ovulation rate in cows

As shown in Table 1, the immunized cows had 3 or 4 waves of follicular development during the estrous cycle, while the control cows had 2 or 3 waves. Moreover, the immunized cows had a significantly greater number of follicles during each follicular wave (Table 2). The maximum number of follicles was $14.8 \pm 1.7$ and $5.4 \pm 0.2$ in the inhibinimmunized and control cows, respectively, during the first follicular wave and $13.9 \pm 1.9$ and $5.6 \pm 0.7$, respectively, during the ovulatory wave. There was a non-significant increase in the diameter of dominant follicles in the immunized cows compared with the control cows (Table 3).

The number of multiple ovulations in cows before and after immunization against inhibin is shown in Table 4. Multiple ovulations increased after inhibin immunization, however, the ovulation rate was highly variable between individuals. 


\section{Discussion}

Ovarian superstimulation is induced primarily in donor cows for embryo transfer or for oocyte collection and in vitro embryo production. The goal of superstimulatory treatment is to induce growth of multiple follicles to produce multiple competent
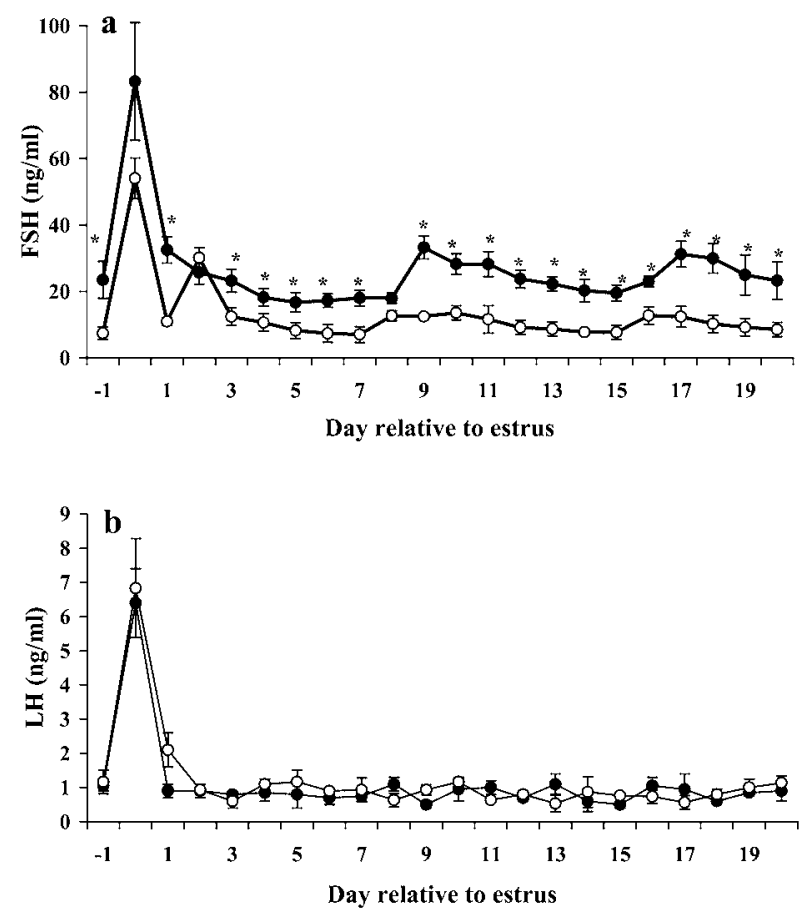

Fig. 2. Plasma concentrations of FSH (a) and LH (b) in the inhibin-immunized (solid circles) or control (open circles) heifers during a complete estrous cycle after the 4 th booster immunization. * Significantly different from the corresponding values in the controls. Values are means \pm SEM for 4 immunized and 6 control animals. oocytes capable of developing into transferable embryos. The present study demonstrated that immunization against inhibin stimulated FSH secretion and ovarian activity in cows. Antibodies against inhibin rose in the inhibin-immunized group after the 2 nd booster immunization, confirming that the increased FSH secretion and ovulation rate after immunization against inhibin $\alpha$-subunit was due to immunoneutralization of endogenous inhibin. Increased plasma levels of FSH in the immunized group were in agreement with those reported previously in cows [16, 20], ewes [10,21] and goats [13]. Immunoneutralization of endogenous inhibin was thought to result in diminished negative feedback on the anterior pituitary gland resulting in increased $\mathrm{FSH}$ secretion, subsequently, increased follicular development, and finally increased ovulation rate. On the other hand, there was no marked change in the LH profile between the immunized and control animals. The stimulation of ovarian activity could be attributed to the stimulatory effect of inhibin immunoeutralization on the ovary, either endocrinologically by removing the inhibitory effect of inhibin on FSH secretion [16, 20, 22] or locally through a paracrine effect $[23,24]$, that

Table 1. Effect of immunization against inhibin on the number of follicular waves during estrous cycle in cows

\begin{tabular}{ccc}
\hline \multirow{2}{*}{$\begin{array}{c}\text { Number of } \\
\text { follicular waves }\end{array}$} & \multicolumn{2}{c}{ Number of cows } \\
\cline { 2 - 3 } & $\begin{array}{c}\text { Control group } \\
(\mathrm{n}=6)\end{array}$ & $\begin{array}{c}\text { Inhibin-immunized } \\
\text { cows }(\mathrm{n}=13)\end{array}$ \\
\hline 2 & 1 & 0 \\
3 & 5 & 3 \\
4 & 0 & 10 \\
\hline
\end{tabular}

Table 2. Time of emergence and the maximum number of follicles in each follicular wave in control cows having 3 follicular waves or inhibin-immunized cows having 4 follicular waves during the estrous cycle

\begin{tabular}{|c|c|c|c|c|}
\hline \multirow{2}{*}{$\begin{array}{l}\text { Follicular } \\
\text { wave }\end{array}$} & \multicolumn{2}{|c|}{ Control group $(n=5)$} & \multicolumn{2}{|c|}{ Inhibin-immunized group $(n=10)$} \\
\hline & Emergence $^{a}$ & $\begin{array}{l}\text { Maximum number } \\
\text { of follicles }\end{array}$ & Emergence $^{a}$ & $\begin{array}{l}\text { Maximum number } \\
\text { of follicles }\end{array}$ \\
\hline 1 st & $3.6 \pm 0.2$ & $5.4 \pm 0.2$ & $2.6 \pm 0.2$ & $14.8 \pm 1.7^{*}$ \\
\hline 2nd & $14.0 \pm 0.7$ & $4.0 \pm 0.0$ & $9.3 \pm 1.0$ & $11.2 \pm 1.2^{*}$ \\
\hline $3 r d$ & - & - & $13.6 \pm 0.9$ & $14.1 \pm 1.1^{*}$ \\
\hline Ovulatory & $18.6 \pm 0.6$ & $5.6 \pm 0.7$ & $18.3 \pm 0.8$ & $13.9 \pm 1.9^{*}$ \\
\hline
\end{tabular}

aThe number of days after the beginning of the estrous cycle. ${ }^{*}$ Significantly different from the controls. Values are means \pm SEM. 
Table 3. The timing and diameter of the maximum dominant follicles in control cows having 3 follicular waves or inhibin-immunized cows having 4 follicular waves during the estrous cycle

\begin{tabular}{lcccc}
\hline \multirow{2}{*}{$\begin{array}{c}\text { Follicular } \\
\text { wave }\end{array}$} & \multicolumn{2}{c}{ Control group $(\mathrm{n}=5)$} & \multicolumn{2}{c}{ Inhibin-immunized group (n=10) } \\
\cline { 2 - 5 } & Timing $^{\mathrm{a}}$ & $\begin{array}{c}\text { Maximum diameter } \\
\text { of DF }(\mathrm{mm})\end{array}$ & Timing $^{\mathrm{a}}$ & $\begin{array}{c}\text { Maximum diameter } \\
\text { of DF (mm) }\end{array}$ \\
\hline 1st & $7.2 \pm 0.5$ & $12.0 \pm 0.3$ & $5.9 \pm 0.7$ & $12.7 \pm 0.4$ \\
\hline 2nd & $15.4 \pm 1.0$ & $10.1 \pm 0.4$ & $12.2 \pm 0.7$ & $13.2 \pm 0.4$ \\
\hline 3rd & - & - & $17.4 \pm 0.7$ & $13.0 \pm 0.6$ \\
Ovulatory & $21.6 \pm 0.7$ & $12.1 \pm 0.6$ & $22.5 \pm 0.5$ & $16.5 \pm 0.5$ \\
\hline
\end{tabular}

a The number of days after the beginning of the estrous cycle. Values are means \pm SEM.

Table 4. The number of ovulations between 2 estrous cycles before and 8 estrous cycles after active immunization against inhibin in cows

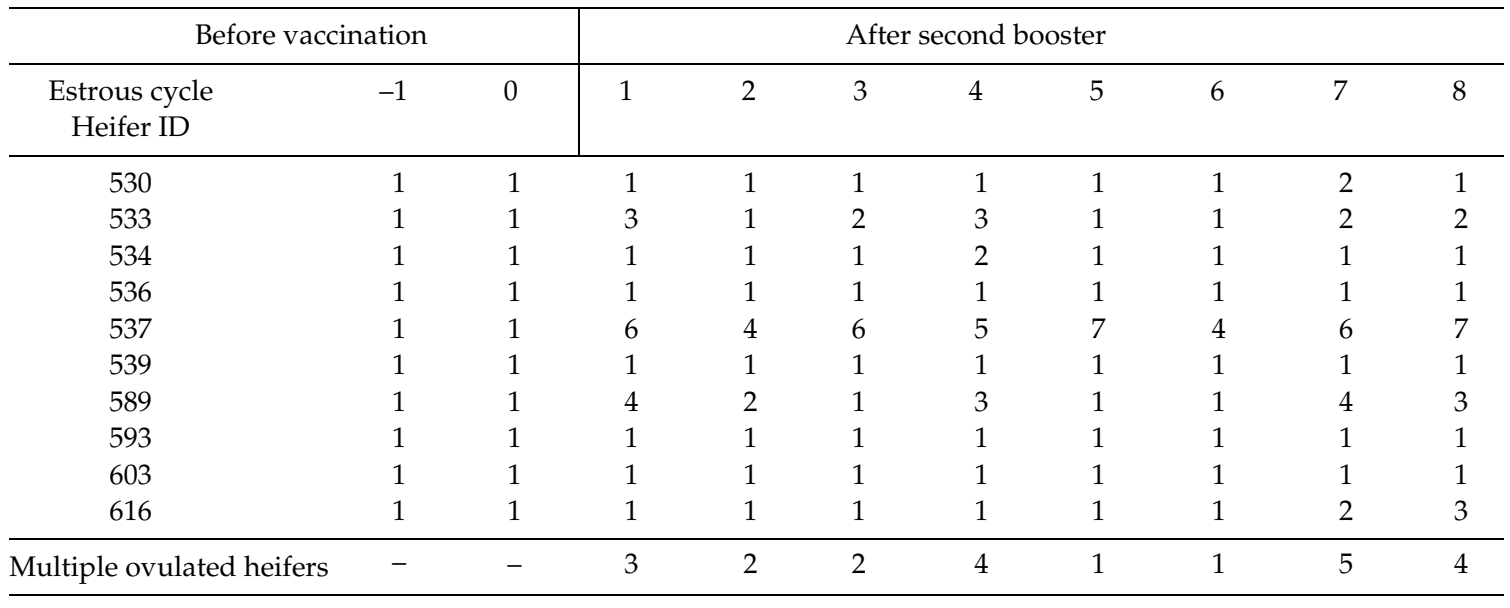

ultimately enhances ovarian follicular development and increases the number of growing follicles.

Previous studies reported that follicular development during the estrous cycles of cows occurs in waves. It has also been stated that 2 or 3 follicular waves occur during the estrous cycle $[1,4$, 25-28]. Transient increases in the concentrations of circulating FSH have been found to be responsible for eliciting periodic emergence of follicular waves $[3,4,29,30]$. The results of one study led the authors to hypothesize that superstimulatory gonadotropin treatments rescue follicles of an existing wave from atresia rather than recruit new follicles into the wave [29]. In this regard, initial findings from separate and independent studies suggest a link between the variability in the number of follicles present at the time of wave emergence and the responsiveness to superstimulatory treatment [31-33]. However, a recent study in sheep [34] showed that creation of physiological peaks of serum FSH concentrations every 2 to 2.5 days stimulated emergence of additional follicular waves. In the present study, the length of the estrous cycle was similar in the immunized and control cows. However, the inhibin-immunized cows had a greater number of follicular waves during the estrous cycle and also a greater number of follicles during each follicular wave. This could be attributed to the increased FSH concentrations in the inhibin-immunized cows or to a paracrine effect. The control heifers had 2 or 3 follicular waves for each interovulatory interval, which is consistent with previous studies [4, 35]. Immunization against inhibin increased the mean number of waves to 3 or 4 follicular waves during the interovulatory interval. An increase in the number of waves can be expected when the emergence of one of the waves is hastened, as shown by cauterization of the dominant follicle of the first wave [36]. Each major wave was associated with a prominent FSH surge, as reported previously $[3,4]$. In the present study, 
immunization against inhibin increased circulating FSH concentrations throughout the estrous cycle. This high level of FSH may hasten the emergence of new follicular waves.

Immunization against inhibin increased multiple ovulations in the present study. However, there was a high variability between individuals. The recorded variability in the ovulation rate in the present study is in agreement with previous studies that found extreme variability in the superstimulatory response of cattle [37,38].

In conclusion, the present study showed that active immunization against inhibin $\alpha$-subunit increased the number of follicular waves and the number of follicles during the estrous cycle in heifers. In addition, the number of multiple ovulations increased in the actively immunized heifers. Therefore, immunization of heifers against inhibin could be a practical method for increasing the number of follicles, which is necessary for oocyte collection and in vitro embryo production.

\section{Acknowledgments}

We are grateful to Dr. D.J. Bolt, USDA, Beltsville, USA, for providing the bovine FSH and LH materials and Dr. Y. Mori, Laboratory of Veterinary Ethology, Department of Veterinary Medical Science, Graduate School of Agricultural and Life Science, The University of Tokyo, Tokyo 113-8657, Japan. This work was supported in part by the Ito Foundation, the Japan Livestock Technology Association, and a Grant-in-Aid for Scientific Research (The 21st Century Center-of-Excellence Program, E-1) from the Ministry of Education, Culture, Sports, Science and Technology of Japan.

\section{References}

1. Ginther OJ, Kastelic JP, Knopf L. Composition and characteristic of follicular waves during the bovine estrous cycle. Anim Reprod Sci 1989; 20: 187-200.

2. Ginther OJ, Beg MA, Donadeu FX, Bergfelt DR. Mechanism of follicle deviation in monovular farm species. Anim Reprod Sci 2003; 78: 239-257.

3. Adams, GP, Matteri RL, Kastelic JP, Ko JCH, Ginther OJ. Association between surges of folliclestimulating hormone and the emergence of follicular waves in heifers. J Reprod Fertil 1992; 94: 177-188.

4. Kaneko H, Kishi H, Watanabe G, Taya K, Sasamoto S, Hasegawa Y. Changes in plasma concentrations of immunoreactive inhibin, estradiol and FSH associated with follicular waves during the estrous cycle of the cow. J Reprod Dev 1995; 41: 311320.

5. Diaz T, Schmitt EJP, de la Sota RL, Thatcher MJ, Thatcher WW. Human chorionic gonadotropininduced alterations in ovarian follicular dynamics during the estrous cycle of heifers. J Anim Sci 1998; 76: 1929-1936.

6. Ginther OJ, Beg MA, Bergfelt DR, Donadeu FX, Kot K. Follicle selection in monovular species. Biol Reprod 2001; 65: 638-647.

7. Kaneko H, Noguchi J, Kikuchi K, Todoroki J, Hasegawa Y. Alterations in peripheral concentrations of inhibin A in cattle studied using a time-resolved immunofluorometric assay: Relationship with estradiol and follicle-stimulating hormone in various reproductive conditions. Biol
Reprod 2002; 67: 38-45.

8. Bodensteiner KJ, Kot K, Wiltbank MC, Ginther OJ. Synchronization of emergence of follicular waves in cattle. Theriogenology 1996; 45: 1115-1128

9. Ginther OJ, Bergfelt DR, Beg MA, Kot K. Role of low circulating FSH concentrations in controlling the interval to emergence of the subsequent follicular wave in cattle. Reproduction 2002; 124: 475482.

10. Mizumachi M, Voglmayr JK, Washington DW, Chen CL, Bardin CW. Superovulation of ewes immunized against the human recombinant inhibin alpha-subunit associated with increased pre- and postovulatory follicle-stimulating hormone levels. Endocrinol 1990; 126: 1058-1063.

11. Wrathall JH, McLeod BJ, Glencross RG, Beard AJ, Knight PG. Inhibin immunoneutralization by antibodies raised against synthetic peptide sequences of inhibin alpha subunit: Effects on gonadotrophin concentrations and ovulation rate in sheep. J Endocrinol 1990; 124: 167-176.

12. Brown RW, Hungerford JW, Greenwood PE, Bloor RJ, Evans DF, Tsonis CG, Forage RG. Immunization against recombinant bovine inhibin alpha subunit causes increased ovulation rates in gilts. J Reprod Fertil 1990; 90: 199-205.

13. Medan MS, Watanabe G, Sasaki K, Nagura $Y$, Sakaime H, Fujita M, Sharawy S, Taya K. Ovarian and hormonal response of female goats to active immunization against inhibin. J Endocrinol 2003; 177: 287-294. 
14. Konishi M, Aoyagi $\mathbf{Y}$, Takedomi $\mathrm{T}$, Itakura $\mathrm{H}$, Itoh T, Yazawa S, Kishi H, Taya K, Watanabe G, Kanagawa $H$. Effect of active immunization of cattle against inhibin on ovarian follicular development and ultrasound-guided transvaginal follicular aspiration. Theriogenology 1996; 46: 33-43.

15. Akagi S, Shi F, Kaneko H, Watanabe G, Tsonis CG, Taya K. Ovarian response and hormonal profiles in heifers after immunization and reimmunization against inhibin $\alpha$-subunit. J Reprod Dev 2002; 48: 599-605.

16. Medan MS, Akagi S, Kaneko H, Watanabe G, Tsonis CG, Taya K. Effects of re-immunization of heifers against inhibin on hormonal profiles and ovulation rate. Reproduction 2004; 128: 475-482.

17. Takedomi T, Kaneko, H, Aoyagi, Y, Konishi M, Kishi H, Watanabe G, Taya K. Effects of passive immunization against inhibin on ovulation rate and embryo recovery in holstein heifers. Theriogenology 1997; 47: 1507-1518.

18. Kaneko $\mathbf{H}$, Nakanishi $\mathbf{Y}$, Taya $\mathbf{K}$, Kishi $\mathbf{H}$, Watanabe G, Sasamoto S, Hasegawa Y. Evidence that inhibin is an important factor in the regulation of FSH secretion during the mid-luteal phase in cows. J Endocrinol 1993; 136: 35-41.

19. SAS. Statistics, Version 6.11, SAS Inst Inc, Cary, NC, USA, 1987.

20. Glencross RG, Bleach EC, Wood SC, Knight PG. Active immunization of heifers against inhibin: Effects on plasma concentrations of gonadotrophins, steroids and ovarian follicular dynamics during prostaglandin-synchronized cycles. J Reprod Fertil 1994; 100: 599-605.

21. Tannetta DS, Fray MD, Wrathall JH, Bleach EC, Glencross RG, Knight PG. Effects of supplementary treatment with bovine growth hormone on hormonal and ovulatory responses to inhibin immunization in ewes. J Reprod Fertil 1997; 110: 255-262.

22. Kaneko H, Taya K, Watanabe G, Noguchi J, Kikuchi K, Shimada A, Hasegawa Y. Inhibin is involved in the suppression of FSH secretion in the growth phase of the dominant follicle during the early luteal phase in cows. Domest Anim Endocrinol 1997; 14: 263-271.

23. Tannetta DS, Feist SA, Bleach EC, Groome NP, Evans LW, Knight PG. Effects of active immunization of sheep against an amino terminal peptide of the inhibin alpha $\mathrm{C}$ subunit on intrafollicular levels of activin A, inhibin A and follistatin. J Endocrinol 1998; 157: 157-168.

24. Hennies M, Voglmayr JK, Dietrich E, Stollmann M, Moeller R, Holtz W. Hormonal response of female goats to active immunization against a recombinant human inhibin alpha-subunit, and establishment of an enzyme-linked immunosorbent assay for caprine follicle-stimulating hormone.
Reprod Domest Anim 2001; 36: 65-71.

25. Sirois J, Fortune JE. Ovarian follicular dynamics during the estrous cycle in heifers monitored by real-time ultrasonography. Biol Reprod 1988; 39: 308 317.

26. Taylor C, Rajamahendran R. Follicular dynamics, corpus luteum growth and regression on in lactating dairy cattle. Can J Anim Sci 1991; 71: 61-68.

27. Fortune JE. Follicular dynamics during the bovine estrous cycle: A limiting factor in improvement of fertility? Anim Reprod Sci 1993; 33: 111-125.

28. Driancourt MA. Regulation of ovarian follicular dynamics in farm animals. Implications for manipulation of reproduction. Theriogenelogy 2001; 55: 1211-1239.

29. Adams GP, Kot K, Ginther OJ. Selection of a dominant follicle and suppression of follicular growth in heifers. Anim Reprod Sci 1993; 30: 259-271.

30. Adams GP, Kot K, Smith CA, Ginther OJ. Effect of the dominant follicle on regression of its subordinates in heifers. Can J Anim Sci 1993; 73: 267-275.

31. Bergfelt DR, Bo GA, Mapletoft RJ, Adams GP. Superovulatory response following ablationinduced follicular wave emergence at random stages of the estrous cycle in cattle. Anim Reprod Sci 1997; 49: 1-12.

32. Singh J, Brogliatii GM, Christensen CR, Adams GP. Active immunization against follistatin and its effect on FSH, follicle development and superovulation in heifers. Theriogenology 1999; 52: 49-66.

33. Cushman RA, DeSouza JC, Hedgpeth VS, Britt $\mathrm{JH}$. Superovulatory response of one ovary is related to the micro- and macroscopic population of follicles in the contralateral ovary of the cow. Biol Reprod 1999; 60: 349-354.

34. Duggavathi R, Bartlewski PM, Agg E, Flint S, Barrett DM, Rawlings NC. The effect of the manipulation of follicle-stimulating hormone (FSH)peak characteristics on follicular wave dynamics in sheep: does an ovarian-independent endogenous rhythm in FSH secretion exist? Biol Reprod 2005; 72: 1466-1474.

35. Ginther OJ, Wiltbank MC, Fricke PM, Gibbons JR, Kot K. Selection of the dominant follicle in cattle. Biol Reprod 1996; 55: 1187-1194.

36. Ko JCH, Kastelic JP, Del Campo MR, Ginther OJ. Effects of a dominant follicle on ovarian follicular dynamics during the estrous cycles in heifers. J Reprod Fertil 1991; 91: 511-519.

37. Keller DS, Teepker G. Effect of variability in response to superovulation on donor cow selection differentials in nucleus breeding schemes. J Dairy Sci 1990; 73: 549-554.

38. Kafi M, McGowan MR. Factors associated with variation in the superovulatory response of cattle. Anim Reprod Sci 1997; 48: 137-157. 